Çukurova Üniversitesi Mühendislik Mimarlık Fakültesi Dergisi, 32(2), ss. 239-251, Haziran 2017

Çukurova University Journal of the Faculty of Engineering and Architecture, 32(2), pp. 239-251, June 2017

\title{
Yüksek Fırın Cürufu ve Perlit İkamesinin Çimentolu Macun Dolgunun Mekanik ve Mikroyapı Özelliklerine Etkisi
}

\author{
Tekin YILMAZ ${ }^{* 1}$, Bayram ERÇIKDI ${ }^{1}$ ve Ferdi CİHANGI'R ${ }^{1}$ \\ ${ }^{1}$ Karadeniz Teknik Üniversitesi, Mühendislik Fakültesi, Maden Mühendisliği Bölümü, Trabzon
}

Geliş tarihi: 15.03.2017 Kabul tarihi: 31.05 .2017

\section{$\ddot{O} z$}

Son yıllarda Portland çimentosu (PÇ) yerine belirli oranlarda doğal ve yapay puzolanların kullanılması, çimentolu macun dolgunun (CPB) dayanım ve duraylılığının iyileştirilmesi, asit ve sülfat etkisine karşı direncinin arttırılması ve bağlayıcı maliyetlerinin azaltılması için oldukça yaygın hale gelmiştir. Bu çalışmada yüksek firın cürufu (YFC) ve perlit (P) ikamesinin CPB'nin mekanik ve mikroyapı özelliklerine etkisi araştırılmıştır. PÇ yerine ağırlıkça \%20 YFC ve P ikame edilerek hazırlanan 84 adet CPB numunesi 7, 14, 28 ve 56 günlük kür süreleri sonunda tek eksenli basınç dayanımı ve gözeneklilik (porozite) testlerine tabi tutulmuştur. YFC'li numuneler 7-14 günde PÇ numunelerine göre daha düşük dayanım üretirken 28-56 günde bu numunelerin basınç dayanımını geçmiştir. Gözeneklilik sonuçları incelendiğinde, YFC'li numunelerin gözenekliliği kür süresinin artmasıyla daha fazla iyileşme göstermiştir. Perlit katkılı numuneler ise basınç dayanımı ve gözeneklilik gelişimi açısından zayıf kalmıştır. Elde edilen bulgular YFC'nin CPB içerisinde belirli oranlarda kullanımının mekanik ve mikroyapı özellikleri açısından faydalı olduğunu göstermiştir.

Anahtar Kelimeler: Basınç dayanımı, Gözeneklilik, Çimentolu macun dolgu, Yüksek firın cürufu, Perlit

\section{Effect of the Partial Replacement of Blast Furnace Slag and Perlite on the Mechanical and Microstructural Properties of Cemented Paste Backfill}

\begin{abstract}
Recently, the utilization of natural and artificial pozzolans for the partial replacement of Ordinary Portland cement (OPC) has become widespread to be increased the strength and durability, be improved the resistance to acid and sulphate effect and be reduced binder costs of cemented paste backfill (CPB). In this study, the effect of partial replacement of blast furnace slag (BFS) and perlite (P) was investigated on the mechanical and microstructural properties of CPB. A total of $84 \mathrm{CPB}$ samples prepared with the replacement of $20 \mathrm{wt} . \%$ of BFS and P were subjected to the uniaxial compressive strength (UCS) and porosity tests at 7,14, 28 and 56 days of curing periods. The CPB samples with replacement of BFS produced lower UCS than OPC samples at 7-14 days, while, they exceeded the UCS of OPC samples at 28-56 days of curing time. When the porosity results were examined, the porosity of BFS samples demonstrated more improvement with increasing the curing times. CPB samples with replacement of
\end{abstract}

*Sorumlu yazar (Corresponding authorr): Tekin YILMAZ, yilmaz.tekin@ktu.edu.tr 
perlite were weak in terms of improvement of UCS and porosity. The findings indicated that the utilization of partial replacement of BFS in CPB is beneficial on the mechanical and microstructural properties of CPB.

Keywords: Compressive strength, Porosity, Cemented paste backfill, Blast furnace slag, Perlite

\section{GíRİ̧̧}

Ülkemiz madencilik endüstrisinde cevher zenginleştirme faaliyetleri sonucunda yaklaşık olarak 30 milyon ton katı atık açığa çıkmaktadır. $\mathrm{Bu}$ atıkların büyük bir kısmı sülfürlü mineral açısından zengin olduğu için tehlikeli atık sınıfına girmektedir ve çevresel sorunlar/şikayetler açısından büyük bir potansiyele sahiptir. Daha önceden atmosferik etkilere açık olarak yerüstü atık sahalarına, atık barajlarına ve derin denizlere depolanan bu atıkların, son yıllarda çimentolu macun dolgu (CPB) yöntemi ile yeraltı üretim boşluklarına depolanması teknik, ekonomik ve çevresel açıdan birçok fayda sağlamıştır. $\mathrm{Bu}$ nedenle çimentolu macun dolgu yöntemi birçok yeraltı madeni için madencilik faaliyetlerinin önemli bir parçasını oluşturmaktadır [1-3].

Çimentolu macun dolgu (CPB), ince boyutlu $(<20 \mu \mathrm{m}$ malzeme miktarı en az \%15) cevher zenginleştirme atıkları (ağırlıkça katı oranı \%75-85), bağlayıcı (katı miktarına göre ağırlıkça \%2-9) ve istenen akışkanlığı ve katı oranını (\%70-85) sağlamak için ilave edilen suyun başarılı bir karışımı olarak ifade edilmektedir [4]. Yeraltı maden işletmelerinde kullanılan çimentolu macun dolgu uygulamasının mekanik davranışında (dayanım, duraylılık vb.) bağlayıcı tipi ve oranı önemli bir rol oynamaktadır. Tipik bir macun dolgu tesisinde, bağlayıcı (çimento) masrafları (her $\% 1$ 'lik çimento artışı için ton başına $1 \$$ maliyet artış1) işletme maliyetlerinin \%50-70'ini oluşturmaktadır [3]. Bu sebepten dolayı macun dolgunun dayanım ve duraylılığını olumsuz yönde etkileyecek faktörlere karşı dirençli olacak şekilde daha düşük maliyetli macun dolgu üretimi için farklı çimento tiplerinin veya Portland çimentosu içerisine farklı puzolanların ilave edilmesi gibi alternatif çözümlerin geliştirilmesi büyük önem arz etmektedir.
Günümüzde puzolanlar, düşük hidratasyon 1S1s1, yüksek nihai dayanım, düşük geçirimlilik (permeabilite), yüksek sülfat dayanımı ve düşük alkali- silika tepkimesi gibi yararları nedeniyle inşaat ve madencilik endüstrisinde yaygın bir şekilde kullanılan temel yapı malzemeleridir [5]. Doğal (tras, zeolit, pomza, volkanik tüfler gibi) ve yapay (uçucu kül, yüksek firın cürufu, taban külü, silis dumanı gibi) puzolanik malzemeler, çimento, beton ve dolgu teknolojisinde hem düşük maliyet hem de çevre dengesi için vazgeçilmez bir unsur olarak yerini almaktadır [6]. Puzolanlar, bünyelerinde özellikle aktif silis gibi kolloidal bileşikleri fazla miktarda bulunduran malzemeler [7] oldukları için hidratasyon sonucu ortaya çıkan kalsiyum hidroksiti $\left(\mathrm{Ca}(\mathrm{OH})_{2}\right)$ bağlayarak çimento içerikli malzemelerin dayanımına katkıda bulunur [8].

Yüksek firın cürufu (YFC); demir üretimi esnasında yan ürün olarak üretilen bir yan sanayi ürünüdür. Demir üretimi için yüksek firında ortalama $1500^{\circ} \mathrm{C}$ sicakliklara kadar isitılan demir cevheri, kok kömürü ve kireçtaşı karışımı eriyik hale geldikten sonra özgül ağırlıklarından dolayı eriyik demir firının alt kısmından alınırken daha hafif olan cüruf ise üst kısımdan alınır. Alınan eriyik cüruf su ile ani soğutulduğunda çok hızlı bir şekilde parçalanır ve bu işlemden dolayı puzolanik özellik (bağlayıcılık) kazanır [9]. YFC'nin kimyasal özellikleri incelendiğinde temel olarak $\mathrm{CaO}-\mathrm{SiO}_{2}-\mathrm{MgO}-\mathrm{Al}_{2} \mathrm{O}_{3}$ sistemlerinden meydana geldiği bilinmektedir. YFC genel itibari ile cams1 fazdan oluşmasına rağmen yüksek firın operasyonuna ve soğutulma şekline bağlı olarak, gehlenite $\left(2 \mathrm{CaO} \cdot \mathrm{Al}_{2} \mathrm{O}_{3} \cdot \mathrm{SiO}_{2}\right), \quad$ mervinit $\left(3 \mathrm{CaO} . \mathrm{MgO} .2 \mathrm{SiO}_{2}\right)$ ve akermanite (2CaO.MgO.2 $\left.\mathrm{SiO}_{2}\right)$ gibi baz1 kristal fazlar da içerebilmektedir [10]. YFC'nin hidrolik bağlayıcı özellik kazanabilmesi; cürufun kimyasal kompozisyonuna, inceliğine ve içerisindeki camsı yapı miktarına bağlıdır [11]. 
Perlit, mineralojik karakter bakımından \%3-10 oranında kristalleşmiş minerallere sahip olan ve obsidyen parçacıkları içeren asidik karakterli volkanik bir camdır. Amorf yapısı ve yüksek $\mathrm{SiO}_{2}$, $\mathrm{Al}_{2} \mathrm{O}_{3}$ ve $\mathrm{Fe}_{2} \mathrm{O}_{3}$ içeriği sebebiyle doğal puzolan sınıfında yer almaktadır [5, 12]. Isıyla genleşme özelliği olan malzeme genleştirildiğinde çok hafif ve gözenekli hale geçer. Ancak perlitin aktif $\mathrm{CaO}$ eksikliğinden dolayı puzolanik karakteristiği olmasına rağmen çimentolaşma yeteneği çok az veya hiç yoktur. $\mathrm{Bu}$ yüzden perlit uygun su içeriğinde ve normal ortam sıcaklığında kireç ve çimento gibi yüksek $\mathrm{CaO}$ içeren materyallerle karıştırıldığında bu eksikliği giderilebilmektedir [13].

Beton ve macun dolgu alanlarında bağlayıcı yerine belirli oranlarda yüksek firın cürufu ve perlitin ikame olarak kullanımına yönelik çeşitli çalışmalar gerçekleştirilmiştir. Emiroğlu ve arkadaşları [6] Portland çimentosu (CEM I 42,5 R) yerine belirli oranlarda $(\% 10, \% 20$ ve \%30) YFC ikame edilmesiyle hazırladıkları beton numunelerini basınç dayanımı deneyine tabi tutmuşlar ve ikame oranının artmasıyla basınç dayanımlarının sırasıyla $\% 20, \quad \% 40$ ve $\% 48$ oranında düştüğünü belirlemişlerdir. Bunun sebebini, kullanılan YFC'nin incelik ve yüzey alanı değerlerinin Portland çimentosuna göre daha az olmasıyla ilişkilendirmişlerdir. Macun dolgu alanında yapılan çalışmalarda; Benzaazoua ve arkadaşları [14] Portland çimentosu (PÇ) yerine \%80 oranında yüksek firın cürufu (YFC) ikamesinin \%5-16 sülfür içeriğine sahip atıklar için uygun olduğunu belirtmiştir. Diğer bir çalışmada sülfürce zengin (\%26 S) atıklar kullanılarak \%50 YFC ikameli macun dolgu numuneleri hazırlanmış ve numunelerin 28 günlük kür süresi sonunda 2,2 kat daha yüksek dayanım ürettiği gözlemlenmiştir [15]. Diğer araştırmacılar bağlayıcı olarak $\% 20$ PC $+\% 80$ YFC kullanılarak hazırlanan macun dolgu numunelerinin en yüksek dayanımı sağladığını ve mikroyapı açısından numunelerin gözeneklerinde boyut küçülmesi olduğunu [16] ve YFC ile portlandit $\left[\mathrm{Ca}(\mathrm{OH})_{2}\right]$ arasındaki puzolanik reaksiyon sonucu oluşan ikincil hidratasyon ürünü (C-S-H vb.) nedeniyle YFC içeren macun dolgu numunelerinin en düşük gözenekliliğe ve ince gözenek yapısına sahip olduğunu [17] belirtmişlerdir. Yu ve arkadaşları [18] öğütülmüş perlitin puzolanik aktivitesinin betonun basınç dayanımına etkisini inceledikleri çalışmalarında bağlayıcı yerine farklı oranlarda (\%10, \%15, \%20, $\% 25, \% 30$ ve \%40) öğütülmüș perlit ikamesi kullanarak beton numuneleri hazırlamışlar ve 3, 28 ve 91 günlük kür süreleri sonunda basınç dayanımına tabi tutmuşlardır. Sonuçlar incelendiğinde erken kür süresinde (3 gün) kontrol beton numuneleri perlit ikameli betonlara göre daha yüksek basınç dayanımı üretirken özellikle 91 gün sonunda tüm ikame oranlarında perlitli betonların dayanımı kontrol numunesini geçmiştir. Bulut ve Tanaçan [5] perlitin puzolanik aktivitesini ve hazırlanan harçların dayanıma etkisini araştırdıkları çalışmalarında perlitin ağırlıkça ikame oranı arttırıldığında basınç dayanımlarının azaldığını bildirmişlerdir.

Bu çalışmada, Portland çimentosu yerine ağırlıç̧a \%20 oranında öğütülmüş yüksek firın cürufu (YFC) ve perlit (P) ikame edilerek hazırlanan macun dolgu numunelerinin $7,14,28$ ve 56 günlük kür süreleri sonunda tek eksenli basınç dayanımı ve gözeneklilik (porozite) deneyleri yapılarak YFC ve $\mathrm{P}$ ikamesinin dolgu numunelerinin mekanik ve mikroyap1 özellikleri üzerindeki etkisi araştırılmıştır.

\section{DENEYSEL ÇALIȘMALAR}

\subsection{Atık Malzeme}

Çimentolu macun dolgu, kısaca atık, bağlayıcı ve karışım suyundan meydana gelmektedir. Deneysel çalışmalarda kullanılan atık malzemeler (pirit atık ve bakır atık) Etibakır Kastamonu-Küre İşletmesi cevher hazırlama tesisi çıkışından alınmış ve 500 kg kapasiteli varillere doldurularak Macun Dolgu Laboratuvarına getirilmiştir. Malvern Mastersizer ile atıklar üzerinde yapılan tane boyut dağılımı analizi sonuçlarına göre $20 \mu \mathrm{m}$ altı malzeme miktarları pirit atık ve bakır atık için sırasıyla ağırlıkça \%48,41 ve \%44,79 olarak belirlenmiştir (Şekil 1). 


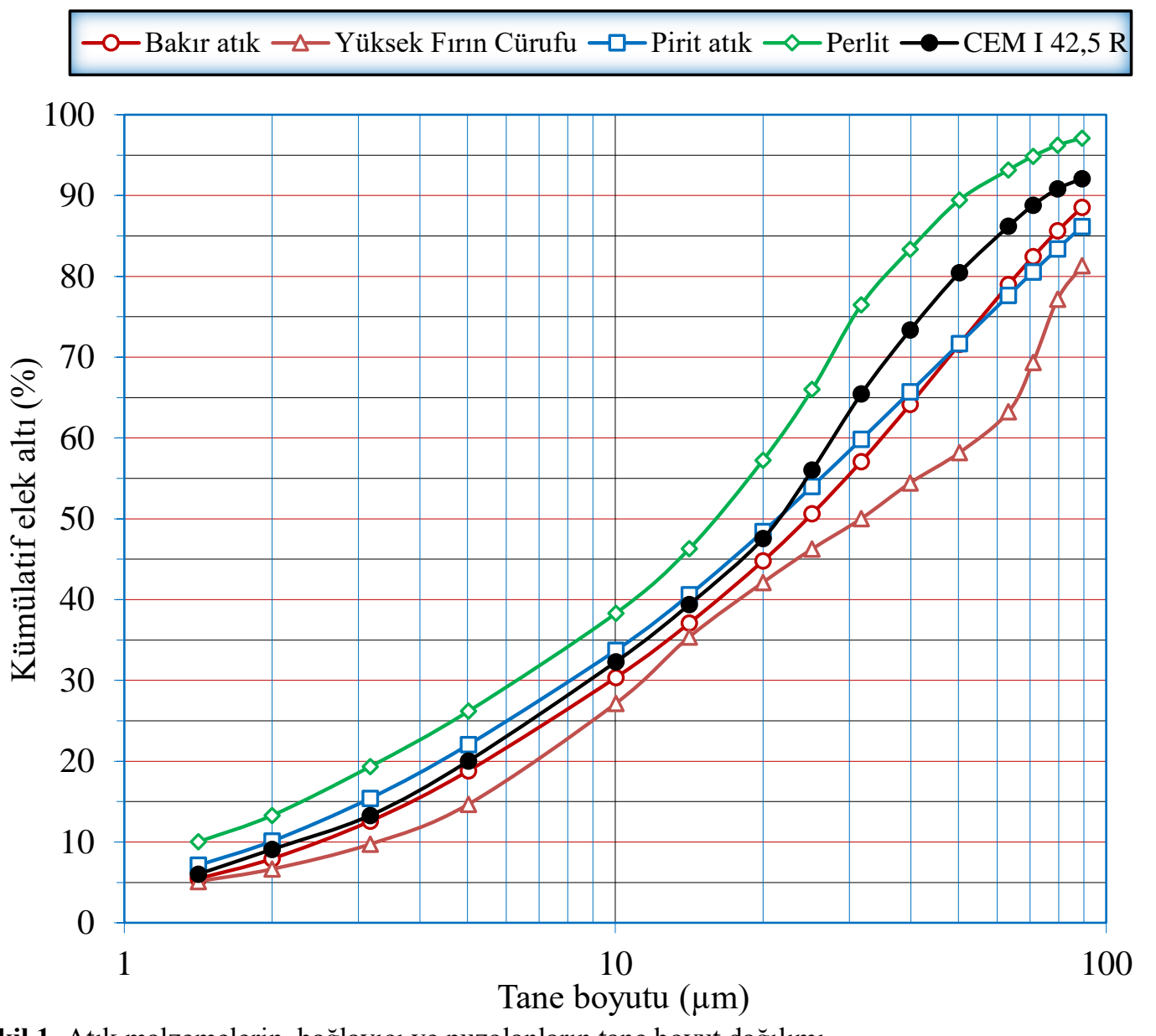

Şekil 1. Atık malzemelerin, bağlayıcı ve puzolanların tane boyut dağılımı

$20 \mu \mathrm{m}$ altı malzeme miktarlarına göre pirit ve

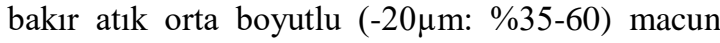
dolgu malzemesi sinıfina girmektedir. Atık malzemelerin kimyasal bileşimini belirlemek için spektrofotometre ve atomik adsorbsiyon spektrometre (AAS) yöntemleri kullanılmış ve sonuçlar Çizelge 1'de verilmiştir. Atık malzemelerin kimyasal bileşimlerine bakıldı ğında her iki atık tipinde de baskın olarak demir (III) oksit $\left(\mathrm{Fe}_{2} \mathrm{O}_{3}\right)$, silisyum dioksit $\left(\mathrm{SiO}_{2}\right)$ minerali bulunduğu, X-1şınları difraktometre (XRD) cihazı kullanılarak elde edilen mineralojik bileşimlerine bakıldığında ise genel olarak atıklar içerisinde kuvars, muskovit, albit, klorit gibi silikat grubu minerallerinin ve baskın olarak pirit $\left(\mathrm{FeS}_{2}\right)$ mineralinin bulunduğu belirlenmiştir.

\subsection{Bağlayıcı Malzeme ve Puzolanlar}

Deneysel çalışmalarda bağlayıcı malzeme olarak; Akçansa çimento fabrikasından temin edilen Portland çimentosu (CEM I 42,5R) kullanılmıştır. Bağlayıcı yerine belirli oranlarda (ağırlıç̧a \%20) ikame olarak kullanılan puzolanlardan yüksek firın cürufu, Kardemir demir-çelik fabrikasından, perlit ise Erper Erzincan Maden İşletmesi'nden temin edilmiştir. Deneysel çalışmalarda kullanılan bağlayıcı malzeme ve puzolanların tane boyut dağılımları Şekil 1'de, fiziksel ve kimyasal özellikleri ise Çizelge 1'de verilmiştir. Bağlayıcı malzeme (Portland çimentosu: CEM I 42,5R) ve puzolanlar (yüksek firın cürufu ve perlit) fiziksel açıdan yeterli inceliğe $\left(\geq 3000 \mathrm{~cm}^{2} / \mathrm{g}\right)$ sahiptir. 
Çizelge 1. Atık, bağlayıcı ve puzolanların fiziksel ve kimyasal özellikleri

\begin{tabular}{|c|c|c|c|c|c|}
\hline Özellikler & $\begin{array}{c}\text { Bakır atık } \\
(\%)\end{array}$ & $\begin{array}{c}\text { Pirit atık } \\
(\%)\end{array}$ & $\begin{array}{c}\text { CEM I 42,5R } \\
(\%)\end{array}$ & $\begin{array}{l}\text { Yüksek Fırın } \\
\text { Cürufu (\%) }\end{array}$ & $\begin{array}{c}\text { Perlit } \\
(\%)\end{array}$ \\
\hline \multicolumn{6}{|l|}{ Kimyasal bileșim } \\
\hline $\mathrm{SiO}_{2}$ & 19,83 & 31,68 & 20,57 & 40,44 & 73,32 \\
\hline $\mathrm{Al}_{2} \mathrm{O}_{3}$ & 5,59 & 9,13 & 4,81 & 11,67 & 13,27 \\
\hline $\mathrm{Fe}_{2} \mathrm{O}_{3}$ & 45,43 & 33,06 & 3,67 & 0,66 & 1,22 \\
\hline $\mathrm{MgO}$ & 2,30 & 3,99 & 1,35 & 6,00 & 0,06 \\
\hline $\mathrm{CaO}$ & 2,20 & 3,50 & 65,27 & 36,42 & 0,84 \\
\hline $\mathrm{Na}_{2} \mathrm{O}$ & 0,36 & 0,79 & 0,41 & 0,28 & 4,09 \\
\hline $\mathrm{SO}_{3}$ & - & - & 2,97 & 1,62 & - \\
\hline $\mathrm{K}_{2} \mathrm{O}$ & 0,29 & 0,38 & 0,85 & 1,25 & 4,40 \\
\hline $\mathrm{TiO}_{2}$ & 0,39 & 0,67 & 0,45 & 1,01 & 0,02 \\
\hline $\mathrm{P}_{2} \mathrm{O}_{5}$ & 0,03 & $<0,01$ & 0,13 & $<0,01$ & 0,01 \\
\hline $\mathrm{MnO}$ & 0,07 & 0,08 & 0,11 & 2,01 & 0,06 \\
\hline $\mathrm{Cr}_{2} \mathrm{O}_{3}$ & 0,023 & 0,035 & 0,075 & 0,007 & 0,003 \\
\hline Serbest $\mathrm{CaO}$ & - & - & 1,19 & - & - \\
\hline Reaktif $\mathrm{SiO}_{2}$ & - & - & - & 39,25 & - \\
\hline Kızdırma kaybı & 22,7 & 16,0 & 2,1 & 0,20 & 0,70 \\
\hline Toplam & 99,21 & 99,33 & 99,90 & 99,87 & 100,03 \\
\hline Sülfür içeriği $\left(\mathrm{S}^{-2}\right)(\%)$ & 29,12 & 16,88 & - & - & - \\
\hline Pirit içeriği $\left(\mathrm{FeS}_{2}\right)(\%)$ & 54,60 & 31,65 & - & - & - \\
\hline \multicolumn{6}{|l|}{ Fiziksel özellikler } \\
\hline Özgül ağırlık (g/cm³) & 3,87 & 3,37 & 3,14 & 2,89 & 2,34 \\
\hline Özgül yüzey alanı $\left(\mathrm{cm}^{2} / \mathrm{g}\right)$ & 3110 & 4440 & 4335 & 4550 & 4260 \\
\hline
\end{tabular}

\subsection{Numunelerin Hazırlanması}

Atık malzemeler, bağlayıcı (Portland çimentosu) malzeme, puzolan malzemeleri (ikame olarak) ve karışım suyu kullanılarak ağırlıkça \%7 bağlayıcı oranı ve 19,05 cm çökme (akışkanlık) değerinde macun dolgu numuneleri hazırlanmıştır. Macun dolgu karışımında kullanılan puzolanlar karışım içerisine Portland çimentosu yerine ağırlıkça \%20 olarak ilave edilmiştir. Karışımların çökme (akışkanlık) değerine $(19,05 \mathrm{~cm})$ göre pirit atık ve bakır atık ile hazırlanan dolgu karışımlarının katı oranları sırasıyla ağırlıkça \%74,71 ve $\% 77,25$ olarak belirlenmiştir (Çizelge 2).

Çizelge 2. Numunelerin hazırlanmasında kullanılan deneysel çalışma koşulları

\begin{tabular}{|c|c|c|c|c|c|c|c|c|}
\hline \multirow{2}{*}{$\begin{array}{c}\text { Atık } \\
\text { tipi }\end{array}$} & \multirow{2}{*}{ Numune ad 1} & \multirow{2}{*}{$\begin{array}{l}\text { Kat1 oran1 } \\
\text { (Ağr. } \%)\end{array}$} & \multirow{2}{*}{$\begin{array}{l}\text { Bağlayıcı oranı } \\
\text { (Ağr. \%) }\end{array}$} & \multicolumn{3}{|c|}{ İkame oranı (Ağr. \%) } & \multirow{2}{*}{$\begin{array}{l}\text { Çökme } \\
\text { (cm) }\end{array}$} & \multirow{2}{*}{$\begin{array}{c}\text { Numune } \\
\text { sayıs1 (84) }\end{array}$} \\
\hline & & & & PÇ & YFC & $\mathrm{P}$ & & \\
\hline \multirow{3}{*}{$\begin{array}{l}\text { Pirit } \\
\text { atık }\end{array}$} & KONTROL & \multirow{3}{*}{74,71} & \multirow{6}{*}{7,0} & 100 & - & - & \multirow{6}{*}{19,05} & 14 \\
\hline & $\% 20 \mathrm{YFC}$ & & & 80 & 20 & - & & 14 \\
\hline & $\% 20 \mathrm{P}$ & & & 80 & - & 20 & & 14 \\
\hline \multirow{3}{*}{$\begin{array}{c}\text { Bakır } \\
\text { atık }\end{array}$} & KONTROL & \multirow{3}{*}{77,25} & & 100 & - & - & & 14 \\
\hline & $\% 20 \mathrm{YFC}$ & & & 80 & 20 & - & & 14 \\
\hline & $\% 20 \mathrm{P}$ & & & 80 & - & 20 & & 14 \\
\hline
\end{tabular}

Karışımın (atık malzeme, bağlayıcı ve su) homojen bir şekilde hazırlanması için karıştırma işlemi 105 devir/dk'llk dönme hızında 7 dakika süreyle yapılmıştır. Hazırlanan dolgu karışımları $5 \times 10 \mathrm{~cm}$ boyutlu drenajlı silindirik macun dolgu kalıplarına yerleştirilmiş ve $\% 80$ nem oranına ve $20^{\circ} \mathrm{C}$ sıcaklığa sahip macun dolgu kür odasında 7, 14, 28 ve 56 günlük kür sürelerinde bekletilmiştir. Tek eksenli basınç dayanımı deneyinde her bir kür süresi için 3 adet olmak üzere iki farklı atık tipinde 
toplam 72 adet, gözeneklilik (porozite) deneyi için 7 ve 56 günlük kür sürelerinde 1'er adet olmak üzere toplam 12 adet numune hazırlanmıştır (Şekil 2).

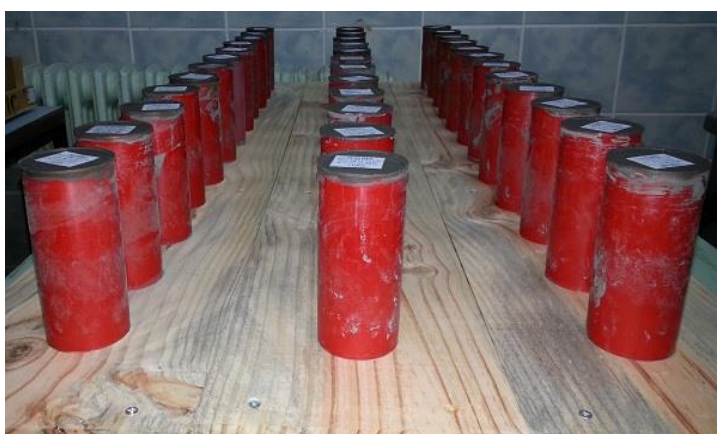

Şekil 2. Macun dolgu numunelerinin görünümü

\subsection{Tek Eksenli Basınç Dayanımı Deneyi}

Macun dolgu numunelerinin tek eksenli basınç dayanımı deneyi, ASTM C 39 [19] tarafından önerilmiş yönteme göre Şekil 3'de görüldüğü gibi önceden belirlenen kür süreleri sonunda yük kapasitesi $50 \mathrm{kN}$ ve $0,5 \mathrm{~mm} / \mathrm{dk}$ 'lık bir yükleme hızına sahip ELE marka bilgisayar kontrollü basınç ve deformasyon ünitesinde gerçekleştirilmiştir.

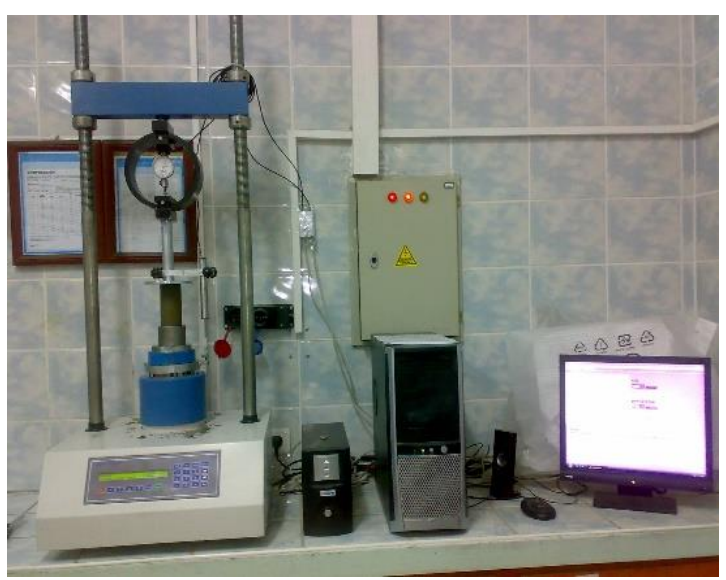

Şekil 3. Tek eksenli basınç dayanımı deneyi

Örneklerin alt ve üst yüzeyleri deneyler öncesinde düzeltilmiştir. Her bir kür süresi için 3 adet numune deneye tabi tutulmuş ve sonuçlar bu numunelerden elde edilen değerlerin ortalaması olarak alınmıştır. Çalışmalarda numunelerin dayanım değerlendirilmesinde; kısa (28 günlük kür süresi) dönem kritik dayanım değerleri 1,0 $\mathrm{MPa}$ olarak esas alınmaktadır [20].

\subsection{Gözeneklilik (Porozite) Analizleri}

Bu çalışmada dolgu numunelerinin 7 ve 56 günlük kür süresi sonundaki gözeneklilik (porozite) değişimlerinin incelenmesi amacıyla gözeneklilik deneyleri gerçekleştirilmiştir. $\mathrm{Bu}$ amaçla hazırlanmış dolgu numuneleri kür süresi sonunda ağırlıklarının sabitlenmesi amacıyla $50^{\circ} \mathrm{C}$ 'de 36 saat süreyle etüvde kurutulmuş ve sonrasında nemden etkilenmemesi için desikatöre konularak soğutulmuştur. Gözeneklilik deneyi için hazır hale gelen numunelerin analizleri, mikro gözeneklere $(<0,003 \mu \mathrm{m})$ civa $(\mathrm{Hg})$ intrüzyonunu sağlayacak şekilde $0-414 \mathrm{MPa}(60,000$ psi) aralığında hidrostatik basınç özelliğine sahip Micromeritics Autopore IV 9410 model civalı Porozimetre (MIP) cihazı kullanılarak ASTM D 4404-10 [21] standardına göre gerçekleştirilmiştir (Şekil 4a).
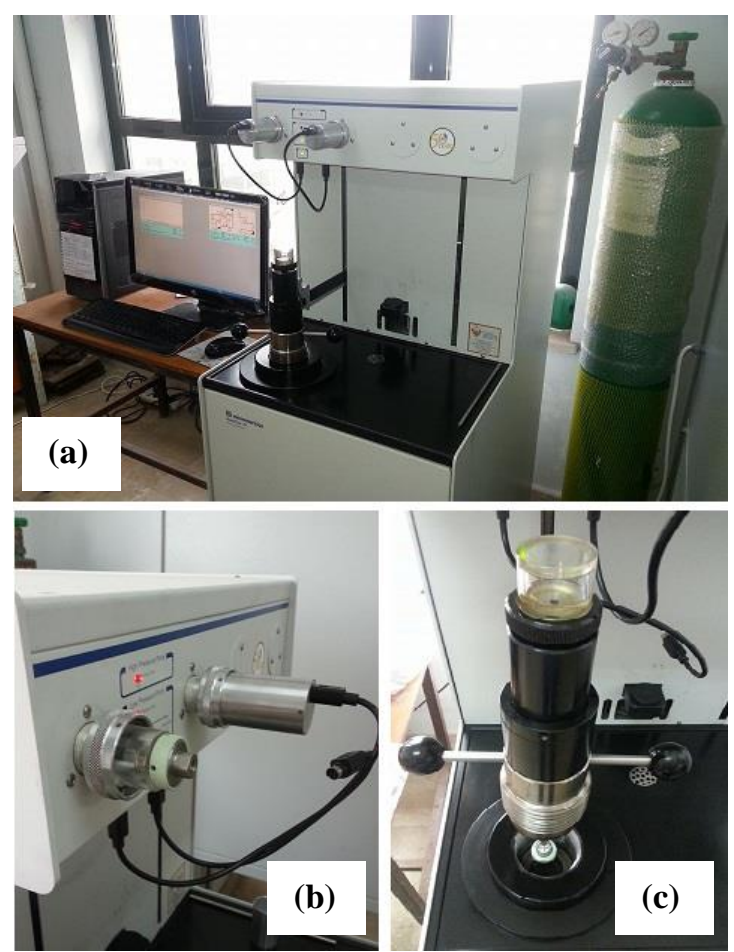

Şekil 4. Bilgisayar kontrollü MIP cihazı (a), alçak (b) ve yüksek basınç ünitesi (c) 
Civalı Porozimetre (MIP) cihazında gözeneklilik deneyi iki aşamalı olarak gerçekleştirilmektedir. İlk aşamada içerisinde numune bulunan penetrometre alçak basınç ünitesine yerleştirilir (Şekil 4b), numune içinde bulunan gazlar buharlaştırılır, penetrometre civa ile doldurulur ve 7-345 $\mathrm{kPa}$ arası basınca kadar gözenek ölçümü yapılır. Daha sonra civa dolu penetrometre yüksek basınç ünitesine yerleştirilir (Şekil 4c) ve $414 \mathrm{MPa}$ (60.000 psi)'a kadar basınç uygulanarak numune içerisindeki gözeneklilik miktarı belirlenir. Deneysel çalışmalarda civa (Hg) yüzey çekimi $0,485 \mathrm{~N} / \mathrm{m}$ ve civa ile numune yüzeyleri arasındaki kontak açısı $130^{\circ}$ olarak alınmıştır [16, 22, 23]. Analizde kullanilacak numune boyutu, penetrometre hacmine bağlı olarak belirlenmiştir. MIP analizleri üretici firmalar tarafindan önerilen penetrometre sap1 hacmi $(\% 25<$ stem volume $<90)$ aralığına uygun olarak gerçekleştirilmiştir.

Analizler sonucunda gözenek karakterizasyonu değerlendirmeleri, Uluslararası Kuramsal ve Uygulamalı Kimya Sinıflaması Birliği'nin [24] çimentolu malzemeler için önerdiği gözenek boyutu sinıflamasına göre yapılmıştır. $\mathrm{Bu}$ sinıflamada 0,002 $\mu$ m'den küçük çapa sahip gözenekler minik gözenek, 0,002-0,05 $\mu \mathrm{m}$ aras1 çapa sahip gözenekler orta boyutlu gözenek, 0,05 $\mu$ m'den büyük çapa sahip gözenekler ise büyük boyutlu gözenek olarak adlandırılmıştır. MIP deneyleri ile orta ve büyük boyutlu gözenekler ölçülebilmektedir.

\section{BULGULAR VE TARTIŞMA}

\subsection{Mekanik Özelliklere Etkisi}

Şekil 5'te pirit atık (a) ve bakır atık (b) kullanılarak $\% 7$ bağlayıcı oranında, sadece Portland çimentosu (kontrol) ve Portland çimentosuna ağırlıkça \%20 oranında YFC ve perlit ikame edilerek hazırlanan çimentolu macun dolgu numunelerinin 7, 14, 28 ve 56 günlük kür süresi sonunda gerçekleştirilen tek eksenli basınç dayanımı (TEBD) sonuçları verilmiştir. Hazırlanan bütün macun dolgu numunelerinin basinç dayanımları karışım özellikleri ve atık tipinden bağımsız olarak kür süresinin artmasıyla birlikte artmıştır. Her iki atık tipinde erken kür sürelerinde (7-14 gün) Portland çimentosu (kontrol) ile hazırlanan numunelerin YFC ve P ikameli dolgu numunelerine göre daha yüksek basınç dayanımı ürettiği belirlenmiştir (Şekil 5a,b). Bu durum puzolanların (yüksek firın cürufu, perlit vb.) hidratasyon 1sılarının daha düşük olmasından dolayı erken kür sürelerinde dayanım kazanımlarının oldukça yavaş olabileceği ile açıklanabilir [25]. İlerleyen kür sürelerinde (28-56 gün) ise YFC ikameli numunelerin kontrol numunelerini yakalayarak geçtiği açıkça görülmektedir ve bu YFC'nin puzolanik aktivitesi ile ilişkilendirilebilir [26]. Ayrıca YFC ile portlandit $\left[\mathrm{Ca}(\mathrm{OH})_{2}\right]$ arasındaki puzolanik reaksiyon sonucu oluşan ikincil hidratasyon ürünü (C-S-H vb.) nedeniyle YFC içeren macun dolgu numunelerinin en düşük gözenekliliğe ve ince gözenek yapısına sahip olduğu belirtilmiştir [17]. $\mathrm{Bu}$ çalışma ile benzer sonuçların elde edildiği başka bir çalışmada ise Türkmen ve arkadaşları [27] Portland çimentosu yerine belirli oranlarda (\%10-30) YFC kullanarak beton numuneleri hazırlamışlar ve 7 gün sonunda Portland çimentolu (kontrol) betonların daha yüksek dayanım ürettiğini fakat 28 ve 90 günde YFC'li betonların basınç dayanımlarının kontrol numunelerini geçtiğini belirtmişlerdir. Perlit (P) ikameli dolgu numuneleri ise her iki atık tipinde kontrol ve YFC'li numunelere göre bütün kür sürelerinde daha düşük basınç dayanımı üretmiştir (Şekil 5a,b). Çalık [13] perlitin düşük dayanım üretmesini, perlitin puzolanik özelliğinin olmasına rağmen aktif $\mathrm{CaO}$ içeriğinin Portland çimentosu ve YFC'ye göre oldukça düşük olması ve bu nedenle bağlayıcılık özelliğinin yetersiz kalması ile ilişkilendirmiştir (Çizelge 1). Ayrıca perlitin özgül yüzey alanı (4260 $\left.\mathrm{cm}^{2} / \mathrm{g}<4335-4550 \quad \mathrm{~cm}^{2} / \mathrm{g}\right)$ Portland çimentosu ve YFC'ye göre daha düşüktür. Şekil 5 incelendiğinde genel olarak bakır atık ile hazırlanan dolgu numunelerinin pirit atık ile hazırlanan numunelere göre daha yüksek basınç dayanımı ürettiği görülmektedir. $\mathrm{Bu}$, atık malzemelerin fiziksel ve kimyasal analiz sonuçlarına göre bakır atığın daha düşük silikat içeriğine $\left(\mathrm{SiO}_{2}+\mathrm{Al}_{2} \mathrm{O}_{3}=\% 25,4<\% 40,8\right)$ sahip olmasından dolayı daha düşük su tutma kapasitesi ve daha düşük ince boyutlu tane içeriğine $(-20 \mu \mathrm{m}$ $=\% 44,79<\% 48,41)$ sahip olmas1 gibi nedenlere dayandırılabilir [28] (Şekil 1 ve Çizelge 1). 28 günlük kritik dayanım değerleri incelendiğinde 
bakır atık ile hazırlanan kontrol $(1,01 \mathrm{MPa})$ ve YFC (1,11 MPa) ikameli numunelerin kritik dayanım değerini geçtiği görülmekte iken pirit atık ile hazırlanan numunelerin yeterli dayanım kazanımını (TEBD $\geq 1,0 \mathrm{MPa})$ sağlayamadı̆̆ belirlenmiştir [20] (Şekil 5).
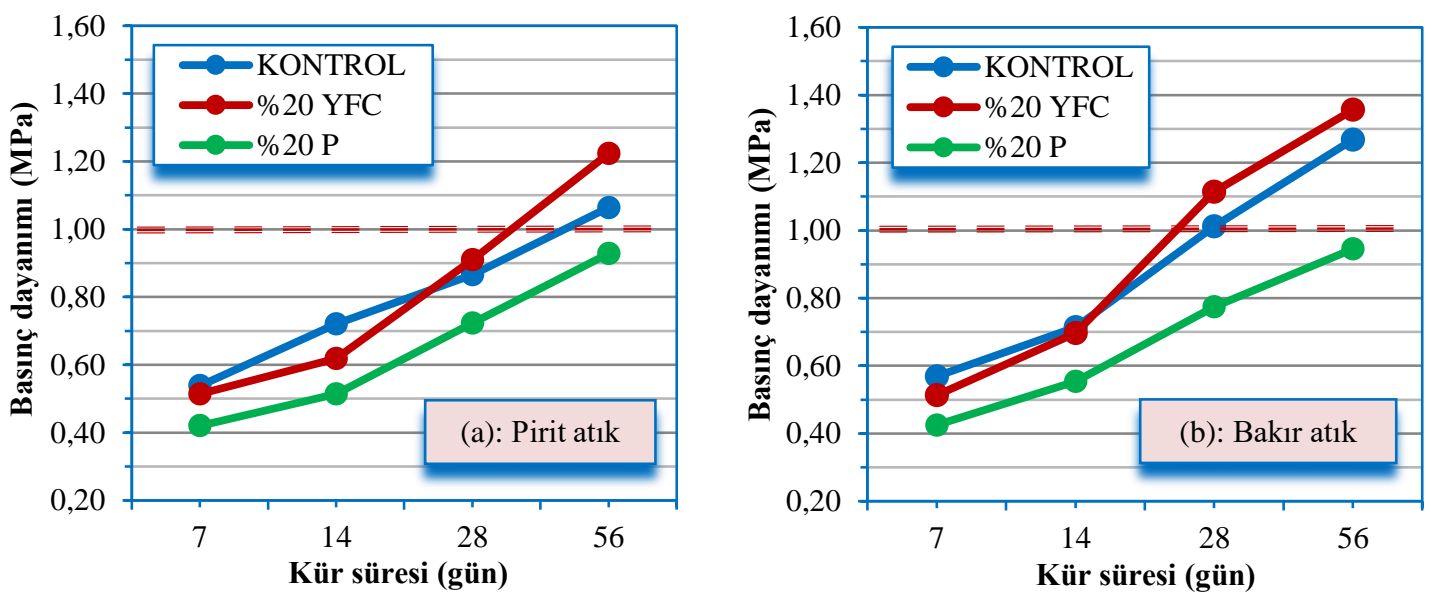

Şekil 5. Yüksek firın cürufu (YFC) ve perlit (P) ikamesinin tek eksenli basınç dayanımına etkisi

\subsection{Mikroyapı Özelliklerine Etkisi}

Pirit atık (PA) ve Bakır atık (BA) kullanılarak Portland çimentosu (Kontrol) ve Portland çimentosuna \%20 YFC ve P ikame edilerek hazırlanan macun dolgu numunelerinin toplam (kümülatif) ve kademeli (artımlı) gözenekliliklerinin (porozitelerinin) değişimi Şekil 6 ve 7'de, gözenek gelişimleri ile ilgili teknik parametreler ise Çizelge 3'de gösterilmiştir. Kür süresinin 7'den 56 güne artmasıly birlikte tüm karışım özelliklerinde atık tipinden bağımsız olarak dolgu numunelerinin toplam gözeneklilik değerlerinin düştüğü açıkça görünmektedir (Şekil 6a,b ve 7a,b). Kür süresinin artmasıyla birlikte dolgu bünyesinde daha fazla bağlayıcı hidratasyon ürününün üretildiği ve bu hidratasyon ürünlerinin gözenekliliği düşürdüğü, gözeneklerin azalmasına/küçülmesine yardımcı olarak dayanım kazanımına katkı sağladığı belirtilmiştir [17]. Macun dolgu numunelerinin gözeneklilik değişimleri incelendiğinde 7 günde kontrol numunelerinin toplam gözeneklilik değerinin YFC ve $P$ ikameli numunelere kıyasla daha düşük çıktığ1 görülmüştür. Fakat 56 gün sonundaki gözeneklilik değişimleri karşılaştırıldığında geçen süre içerisinde atık tipinden bağımsız olarak YFC'li numunelerin büyük boyutlu gözenek miktarlarının kontrol ve $\mathrm{P}$ ikameli numunelere göre daha fazla azaldığı ve bu sayede toplam gözenekliliğinin düştüğü belirlenmiştir (Şekil 6a,b ve 7a,b) (Çizelge 3). Gözeneklilik değişimi farklılığının sebebi, Portland çimentosunun kimyasal bileşiminden dolayı erken kür sürelerinde daha hızlı bir hidratasyon süreci geçirmesi ve daha fazla hidratasyon ürününün meydana gelmesi olabilirken [3] ilerleyen kür sürelerinde YFC'li numunelerdeki gözeneklilik düşüşünün daha fazla olması YFC'nin puzolanik özelliğinden dolayı dolgu numunesi içerisindeki boşlukları doldurması olabilir. Dolgu numunelerinin (Kontrol, \%20 YFC ve \%20 P) 7-56 gün arasındaki gözeneklilik değişimleri analiz edildiğinde PA'da sırasıyla $\% 4,24, \% 10,87$ ve $\% 4,50$ oranında, $\mathrm{BA}^{\prime} \mathrm{da}$ ise $\% 5,80, \% 14,85$ ve $\% 6,41$ oranında azalma meydana gelmiştir. Perlit (P) ikameli dolgu numunelerinin toplam gözeneklilik değerleri ise 7 ve 56 gün sonunda diğer numunelere göre daha yüksek çıkmıştır. $\mathrm{Bu}$ durum, perlitin puzolanik özellik göstermesine karşın YFC'ye kıyasla çok daha düşük $\mathrm{CaO}$ içeriğine (Çizelge 1) sahip olması ve yüksek hidratasyon isısına ihtiyaç duymasından dolayı ilave hidratasyon ürünleri (C-S-H) üretememesi sonucu ilerleyen kür sürelerinde büyük boyutlu gözeneklerin (Çizelge 3) azalmamasıyla ilişkilendirilebilir [13]. 

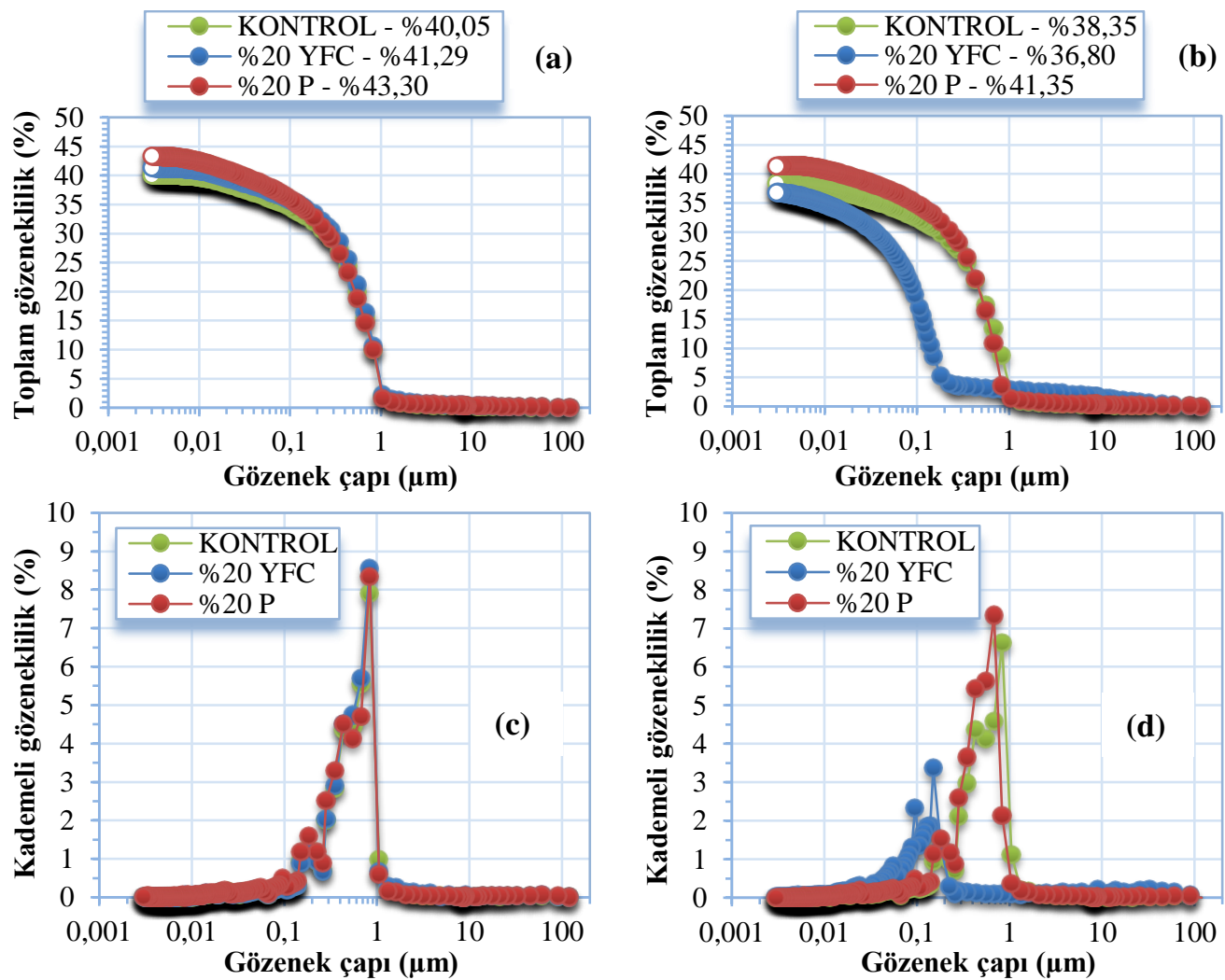

Şekil 6. PA kullanılan CPB'nin 7 (a,c) ve 56 (b,d) gündeki toplam $(\mathrm{a}, \mathrm{b})$ ve kademeli $(\mathrm{c}, \mathrm{d})$ gözeneklilik değişimleri

Ghirian ve Fall [29] bağlayıcı hidratasyonu prosesinden kaynaklanan gözenek yapısı gelişiminin MIP sonuçlarının incelenmesiyle anlaşılabileceğini bildirmişlerdir. Bu bağlamda 7 ve 150 günlük numunelerin sonuçlarını analiz ettiklerinde 7 günde 1-3 $\mu \mathrm{m}$ arasındaki gözenek dağılımının $\% 71$ iken 150 günde gözenek dağılımının daha ince boyuta doğru yön değiştirmiş ve 0,5-1 $\mu \mathrm{m}$ arası dağılımın \%59 olduğunu ve 150 gündeki dolgu numunelerinde küçük gözenek gelişiminin $(<0,5 \mu \mathrm{m})$ arttığını belirlemişlerdir. Bu çalışmada PA'da orta boyutlu $(0,02-0,05 \mu \mathrm{m})$ ve büyük boyutlu $(>0,05 \mu \mathrm{m})$ gözeneklerin gelişimi incelendiğinde 7 günde kontrol ve YFC'li numunelerin büyük boyutlu gözenek dağılımı \%91 iken 56 günde büyük boyutlu gözenek dağılımları azalarak \%89 ve $\% 73$ olarak gerçekleşmiştir. Buna karşın 56 gündeki orta boyutlu gözenek dağılımları karşılaştırıldığında kontrol numunelerin dağılım değeri \%5 iken YFC'li numunelerin dağılım değeri \%15 olarak belirlenmiştir. BA ile hazırlanan numunelerde de benzer sonuçlar elde edilmiştir. $\mathrm{Bu}$ gelişim, gözenek yapısını küçülten ve yoğunlaştıran bağlayıcı hidratasyon ürünlerinden kaynaklı küçük gözeneklerin doldurulması ile ilişkilendirilebilir [29].

Atık malzemenin $20 \mu \mathrm{m}$ alt malzeme miktarı macun dolgunun mikroyapısı (toplam gözeneklilik, boşluk oranı vb.) için kritik öneme sahiptir. Toplam (kümülatif) gözenekliliğin atı̆̆ın ince boyutlu tane içeriğinin artmasıla artma eğiliminde olduğu bildirilmiştir $[30,31]$. Şekil $6 a, b$ ve $7 a, b$ incelendiğinde PA'nın ince boyutlu tane $(\% 48,4>\% 44,8)$ içeriğinin BA'ya göre daha yüksek olmasından dolayı PA ile hazırlanan dolgu numunelerinin tüm karşım özelliklerinde (PA'da 
\%20 YFC'li 7 günlük numune hariç) 7 ve 56 gün sonunda toplam gözeneklilik değerlerinin BA'lı numunelere kıyasla daha yüksek olduğu görülmektedir (Çizelge 3).
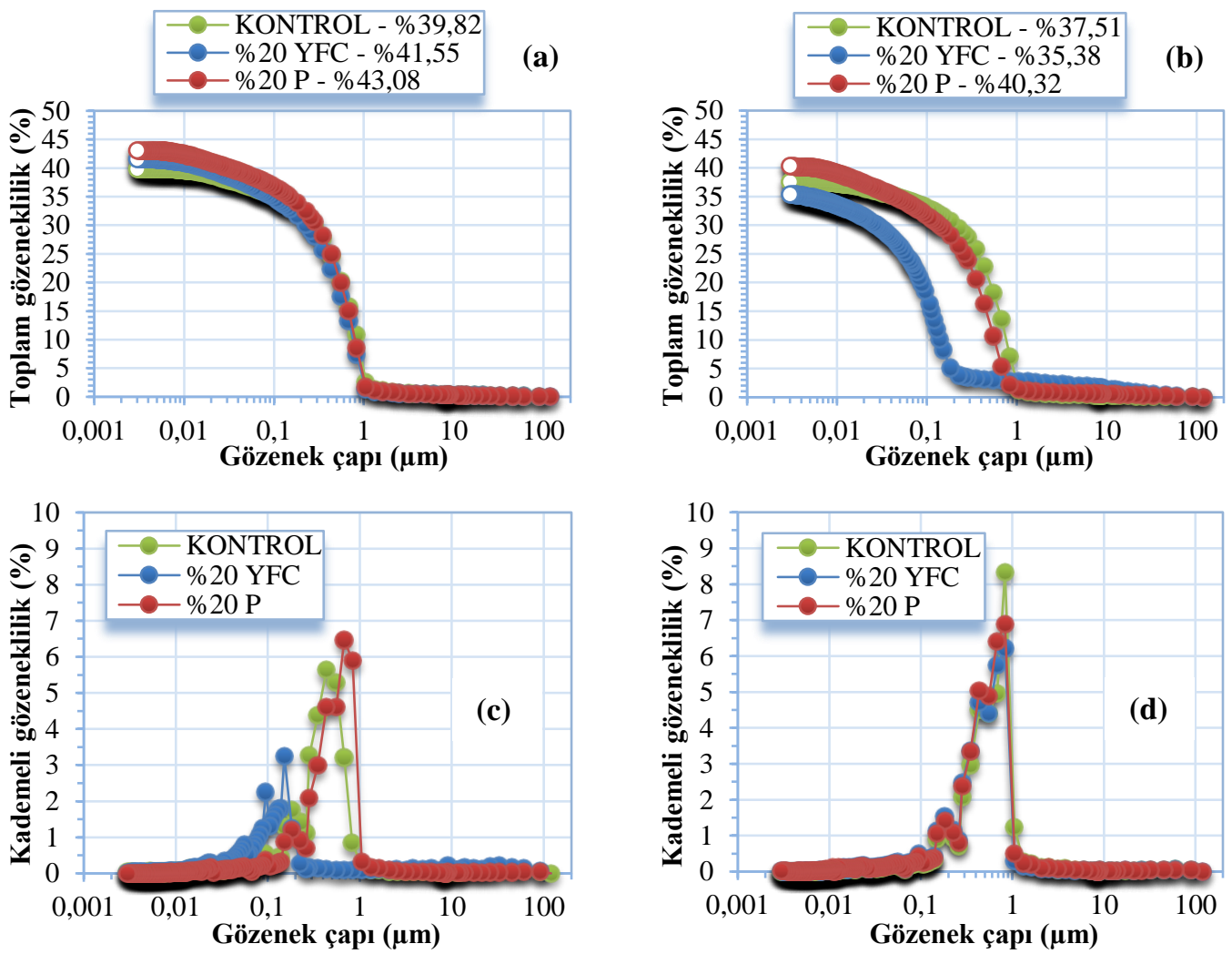

Şekil 7. BA kullanılan CPB'nin $7(\mathrm{a}, \mathrm{c})$ ve 56 (b,d) gündeki toplam (a,b) ve kademeli (c,d) gözeneklilik değişimleri

Çizelge 3. Dolgu numunelerinin gözenek gelişimleri ile ilgili teknik parametreler

\begin{tabular}{|c|c|c|c|c|c|}
\hline \multirow[b]{2}{*}{$\begin{array}{l}\text { Attk } \\
\text { tipi }\end{array}$} & \multirow[b]{2}{*}{ Numune adı } & \multirow[b]{2}{*}{$\begin{array}{l}\text { Kür süresi } \\
\text { (gün) }\end{array}$} & \multirow[b]{2}{*}{$\begin{array}{l}\text { Toplam gözeneklilik } \\
(\%)\end{array}$} & \multicolumn{2}{|c|}{ Toplam gözeneklilik (\%) } \\
\hline & & & & $\begin{array}{c}\text { (a) Orta boyutlu gözenek } \\
(\%)\end{array}$ & $\begin{array}{l}\text { (b) Büyük boyutlu } \\
\text { gözenek (\%) }\end{array}$ \\
\hline \multirow{6}{*}{ PA } & KONTROL & & 40,05 & 2,22 & 36,45 \\
\hline & $\% 20 \mathrm{YFC}$ & 7 & 41,29 & 2,04 & 37,59 \\
\hline & $\% 20 \mathrm{P}$ & & 43,30 & 2,50 & 38,38 \\
\hline & KONTROL & & 38,35 & 2,15 & 34,42 \\
\hline & $\% 20 \mathrm{YFC}$ & 56 & 36,80 & 5,51 & 27,11 \\
\hline & $\% 20 \mathrm{P}$ & & 41,35 & 2,39 & 37,11 \\
\hline \multirow{6}{*}{ BA } & KONTROL & & 39,82 & 1,99 & 36,84 \\
\hline & $\% 20$ YFC & 7 & 41,55 & 2,55 & 37,20 \\
\hline & $\% 20 \mathrm{P}$ & & 43,08 & 2,24 & 38,82 \\
\hline & KONTROL & & 37,51 & 1,84 & 34,72 \\
\hline & $\% 20 \mathrm{YFC}$ & 56 & 35,38 & 5,43 & 26,06 \\
\hline & $\% 20 \mathrm{P}$ & & 40,32 & 2,89 & 34,46 \\
\hline
\end{tabular}

(a) Orta boyutlu gözenek: 0,02-0,05 $\mu \mathrm{m}$ arasındaki gözeneklerin gözeneklilik değeri

(b) Büyük boyutlu gözenek: $0,05 \mu \mathrm{m}$ 'den büyük gözeneklere ait gözeneklilik değeri 


\section{SONUÇLAR}

Bu çalışmada Kastamonu-Küre Etibakır İşletmeleri cevher zenginleştirme tesisi çıkışından alınan Pirit atık ve Bakır atık kullanılarak sadece Portland çimentosu (kontrol) ile ve Portland çimentosuna sırasıyla \%20 yüksek fırın cürufu (YFC) ve Perlit (P) ikame edilerek $5 \times 10 \mathrm{~cm}$ boyutlu silindirik macun dolgu numuneleri hazırlanmıştır. 7, 14, 28 ve 56 günlük kür süreleri sonunda tek eksenli basınç dayanımı deneyleri ile 7 ve 56 günlük kür süreleri sonunda gözeneklilik (porozite) deneyleri gerçekleştirilerek puzolanların (YFC ve Perlit) macun dolgunun mekanik ve mikroyap1 özelliklerine etkisi incelenmiştir. Genel olarak kür süresinin artmasıyla tüm karışım özelliklerinde ve atık tipinden bağımsız olarak dolgu numunelerinin basınç dayanımı artmıştır. Karışım özelliklerinin etkisi karşılaştırıldığında erken kür sürelerinde (7-14 gün) kontrol dolgu numuneleri YFC ve P'li numunelere kıyasla daha yüksek basınç dayanımı üretirken ilerleyen kür sürelerinde (28-56 gün) YFC'li numuneler kontrol numunelerini yakalayarak geçmiştir. Perlit (P) ikameli numunelerin basınç dayanımı ise tüm kür sürelerinde daha düşük seyretmiştir. Mikroyap1 özelliklerinin değerlendirilmesi için yapılan gözeneklilik (porozite) deneylerine göre; basınç dayanımı sonuçlarıyla benzer olarak YFC ikameli dolgu numunelerinin gözenekliliği 7 günde kontrol numunelerine göre daha yüksek, 56 günde ise büyük boyutlu gözeneklerin orta boyutlu gözeneklere dönüşmesiyle birlikte daha düşük çıkmıştır. P ikameli dolgu numunelerinin gözeneklilik değerlerinde ise kür süresiyle birlikte daha az düşüş meydana gelmiştir.

Sonuç olarak yüksek firın cürufunun macun dolguda belirli oranlarda bağlayıcı yerine kullanılmasıyla dolgunun mekanik ve mikroyapı özelliklerinde iyileşme meydana geldiği açıkça görülmüştür. $\mathrm{Bu}$ sayede macun dolgu işletme maliyetlerinde büyük bir payı olan bağlayıcı (çimento) giderlerinde bir miktar tasarruf yapılabileceği düşünülmektedir.

\section{KAYNAKLAR}

1. Yumlu, M., 2010. Pastefill - Becoming a Feasible and Popular Option for Ensuring Recovery of High Grade Deposits, Cobar Mining Seminar 2010, The Australasian Institute of Mining \& Metallurgy, p. 26, New South Wales, Australia.

2. Erçıkdı, B., Cihangir, F., Kesimal, A., Deveci, H., 2012. Tesis Atıklarının Yönetiminde Macun Dolgu Teknolojisi, Madencilik Türkiye, 24, s. 54-59.

3. Yilmaz, T., 2013. Numune Boyutunun Macun Dolgu Dayanımına ve Ultrasonik P- Dalga Hızına Etkisi, Yüksek Lisans Tezi, Karadeniz Teknik Üniversitesi, Fen Bilimleri Enstitüsü, s. 91, Trabzon.

4. Y1lmaz, T., Ercikdi, B., 2016. Predicting the Uniaxial Compressive Strength of Cemented Paste Backfill from Ultrasonic Pulse Velocity Test, Nondestructive Testing and Evaluation, 31,3, p. 247-266.

5. Bulut, Ü., Tanaçan, L., 2009. Perlitin Puzolanik Aktivitesi, İTÜ Dergisi/a Mimarlık, Planlama, Tasarım, 8,1, s. 81-89.

6. Emiroğlu, M., Koçak, Y., Subaşı, S., 2011. Yüksek Firın Cürufunun Betonun Fiziksel ve Mekanik Özelliklerine Etkisi, $6^{\text {th }}$ International Advanced Technologies Symposium (IATS'11), 16-18 May 2011, Elazığ, Turkey, p. 113-117.

7. Topçu, İ.B., 2006. Beton. TMMOB İnşaat Mühendisleri Odası Eskişehir Şubesi Yayını, No. 2, Eskişehir.

8. Poon, C.S., Lam, L., Kou, S.C., Lin, Z.S., 1999. A Study on The Hydration Rate of Natural Zeolite Blended Cement Pastes, Cement and Concrete Research, 13,8, p. 427432.

9. Cihangir, F., 2016. Yüksek Fırın Cürufu, Üretimi, Özellikleri, Kullanım Alanları ve Sağladığı Avantajlar, International Black Sea Mining \& Tunneling Symposium, 2-4 November 2016, Trabzon-Turkey, p. 361-368.

10. Li, C., Sun, H., Li, L., 2010. A Review: The Comparison Between Alkali-Activated Slag $(\mathrm{Si}+\mathrm{Ca})$ and Metakaolin $(\mathrm{Si}+\mathrm{Al})$ Cements, Cement and Concrete Research, 40,9, p. 1341-1349. 
11. Tokyay, M., 2003. Cüruflar ve Cüruflu Çimentolar, Araştırmaların Gözden Geçirilmesi ve Durum Değerlendirmesi Raporu, TÇMB, Ankara, s. 47.

12. Erdem, T.K., Meral, Ç., Tokyay, M., Erdoğan, T.Y., 2007. Use of Perlite as a Pozzolanic Addition in Producing Blended Cements, Cement and Concrete Composites, 29, s.13-21.

13. Çalık, Ü., 2012. Perlitin Puzolanik Katkı Olarak Kireç ile Birlikte Zemin Stabilizasyonunda Kullanımı, Doktora Tezi, Karadeniz Teknik Üniversitesi, Fen Bilimleri Enstitüsü, s.159, Trabzon.

14. Benzaazoua, M., Belem, T., Bussiere, B., 2002. Chemical Factors that Influence the Performance of Mine Sulphidic Paste Backfill, Cement and Concrete Research, 32,7, p.1133-1144.

15. Fall, M., Belem, T., Samb, S., Benzaazoua, M., 2007. Experimental Characterization of The Stress-Strain Behaviour of Cemented Paste Backfill in Compression, Journal of Materials Science, 42, p. 3914-3922.

16. Ouellet, S., Bussiere, B., Aubertin, M., Benzaazoua, M., 2007. Microstructural Evolution of Cemented Paste Backfill: Mercury Intrusion Porosimetry Test Results, Cement and Concrete Research, 37,12, p. 1654-1665.

17. Fall, M., Celestin, J. C., Pokharel, M., Toure, M., 2010. A Contribution to Understanding the Effects of Curing Temperature on the Mechanical Properties of Mine Cemented Tailings Backfill, Engineering Geology, 114, 3-4, p. 397-413.

18. Yu, L. H., Ou, H., Lee, L. L., 2003. Investigation on Pozzolanic Effect of Perlite Powder in Concrete, Cement and Concrete Research, 33, p. 73-76.

19. ASTM C 39, 2012. Standard Test Method for Compressive Strength of Cylindrical Concrete Specimens, Annual Book of ASTM Standards, American Society of Testing Material.

20. M. Yumlu., 2001. Backfill Practices at Cayeli Mine. In Proc. of the International Mining Conference, Ankara, Turkey, p. 333-339.

21. ASTM D4404-10, 2010. Standard Test Method for Determination of Pore Volume and Pore Volume Distribution of Soil and Rock by
Mercury Intrusion Porosimetry, Annual Book of ASTM Standards, American Society of Testing Material.

22. Cihangir, F., Akyol, Y., 2016. Mechanical, Hydrological and Microstructural Assessment of the Durability of Cemented Paste Backfill Containing Alkali-Activated Slag, International Journal of Mining, Reclamation and Environment, doi.org/10.1080/17480930.2016.1242183.

23. Zheng, J., Zhu, Y., Zhao, Z., 2016. Utilization of Limestone Powder and Water-Reducing Admixture in Cemented Paste Backfill of Coarse Copper Mine Tailings, Construction and Building Materials, 124, p. 31-36.

24. IUPAC, 1972. Manual of Symbols and Terminology. Appendix 2-Part 1: Colloid and Surface Chemistry, Journal of Pure and Applied Chemistry. 31, p. 578-593

25. Demirboğa, R., Türkmen, İ., Karakoç, M. B., 2004. Relationship between Ultrasonic Velocity and Compressive Strength for HighVolume Mineral-Admixtured Concrete, Cement Concrete Res. 34, p. 2329-2336.

26. Ercikdi, B., Cihangir, F., Kesimal, A., Deveci, H., Alp, İ., 2009. Utilization of Industrial Waste Products as Pozzolanic Material in Cemented Paste Backfill of High Sulphide Mill Tailings, Journal of Hazardous Materials 168, p. 848-856.

27. Türkmen, İ., Öz, A., Aydın, A. C., 2010. Characteristics of Workability, Strength and Ultrasonic Pulse Velocity of SCC Containing Zeolite and Slag, Scientific Research and Essays, 5,15, p. 2055-2064.

28. Ercikdi, B., Yılmaz, T., Külekçi, K., 2014. Strength and Ultrasonic Properties of Cemented Paste Backfill, Ultrasonics 54,1, p. 1386-1394.

29. Ghirian, A., Fall, M., 2014. Coupled ThermoHydro-Mechanical-Chemical Behaviour of Cemented Paste Backfill in Column Experiments: Part II: Mechanical, Chemical and Microstructural Processes and Characteristics, Engineering Geology, 170, p. 11-23.

30. Fall, M., Benzaazoua, M., Ouellet, S., 2005. Experimental Characterization of the Influence of Tailings Fineness and Density on the 
Quality of Cemented Paste Backfill, Minerals Engineering. 18,1, p. 41-44.

31. Ercikdi, B., Baki, H., İzki, M., 2013. Effect of Desliming of Sulphide-Rich Mill Tailings on the Long-Term Strength of Cemented Paste Backfill, Journal of Environmental Management, 115, p. 5-13. 